\title{
Comparison of the accuracy of different definitions of clinical remission (CR) and minimal disease activity (MDA) in juvenile idiopathic arthritis (JIA)

\author{
S Davi* , A Consolaro, C Ferrari, S Federici, R Vitale, G Filocamo, A Loy, \\ $\mathrm{N}$ Ruperto, A Martini and A Ravelli
}

Address: IRCCS G. Gaslini, Genoa, Italy

* Corresponding author

from 15th Paediatric Rheumatology European Society (PreS) Congress

London, UK. 14-17 September 2008

Published: 15 September 2008

Pediatric Rheumatology 2008, 6(SuppI I):PI I2 doi:I0.II86/I546-0096-6-SI-PI I 2

This abstract is available from: http://www.ped-rheum.com/content/6/SI/PII2

(c) 2008 Davì et al; licensee BioMed Central Ltd.

\section{Background}

Since the introduction of biologic agents, expectations of medical treatment for chronic arthritides have increased markedly. It is now agreed upon that estimation of effectiveness of these drugs requires not only the assessment of relative improvement in signs and symptoms, but the evaluation of their ability to induce a state of CR or, at least, MDA. In recent years, several criteria for assessing CR and MDA in adult rheumatoid arthritis (RA) or JIA have been developed.

\section{Objective}

To apply existing definitions of CR or MDA in a large sample of visits made in JIA patients.

\section{Methods}

851 visits made in 446 patients between 1992 and 2006 were assessed. CR was defined as achieving: 1) DAS28 score $<2.4 ; 2$ ) SDAI score $\leq 3.3 ; 3$ ) CDAI score $\leq 2.8 ; 4$ ) Clinical remission criteria for RA; 5 ) preliminary definition of CR for JIA. LDA was defined as achieving: 1) DAS28 score $<3.6$; 2) SDAI score $\leq 11$; 3 ) CDAI score $\leq 10$; 3) LDA criteria for RA; 4) LDA criteria for JIA.

\section{Results}

Table 1: shows the percentage of patients classified in state of CR or MDA by each criterion.

\section{Conclusion}

Definition of CR in JIA proved more restrictive than correspondent definitions for adult RA. The proportion of patients classified in MDA by JIA criteria and DAS28, CDAI and SDAI criteria was similar, whereas RA criteria for LDA led to classify relatively more patients in such state.

Table I: The percentage of patients classified in state of CR or MDA by each criterion

\begin{tabular}{llllll}
\hline & DAS28 & SDAI & CDAI & RA criteria & JIA criteria \\
\hline CR & 19.3 & 19.2 & 18.7 & 13.0 & 10.8 \\
MDA & 25.7 & 23.4 & 22.7 & 38.3 & 21.9
\end{tabular}

